\title{
Quality of Actions to Control Cervical Cancer in Bahia, Brazil
}

\author{
Eduarda Ferreira dos Anjos ${ }^{1}$, Poliana Cardoso Martins ${ }^{1}$, Nília Maria Brito de \\ Lima Prado', Vanessa Moraes Bezerra ${ }^{1}$, Patty Fidelis de Almeida ${ }^{2}$, Adriano Maia \\ dos Santos ${ }^{1 *}$
}

\begin{abstract}
Objective: To assess the quality of the actions to control cervical cancer (CC) and its correlates. Methods: This is a cross-sectional study conducted from January to March 2019 in 19 municipalities in Bahia, Brazil, with a sample of 241 doctors and nurses from primary health care (PHC). Three dependent variables were chosen- "Performance of educational, promotion, prevention, and monitoring actions" (D1); "Access to diagnostic tests" (D2); "Non-occurrence of high grade cervical squamous intraepithelial lesions (HSIL)" (D3). Poisson regression with robust variance was used, adopting hierarchical input variables to estimate the prevalence ratios and confidence intervals of $95 \%$. Results: The following prevalence rates were found: D1 39.8\% (95\% CI: 33.8-46.2); D2 73.9\% (95\% CI: 67.9-79.1); and D3 46.4\% (95\% CI: 39.9-53.0). These dimensions remained associated with the dependent variables: D1- having professional training courses on the topic; consideration to ensure that collection takes place appropriately by a professional; and women having access to medical transport; D2- nurses treating low-grade lesions; D3- recording the Papanicolaou in electronic medical records; D1 and D2- professionals joining the service through public tender; D1 and D3- working in the PHC ( $\geq 2$ years); D2 and D3- recording Papanicolaou in physical records; and performance of Papanicolaou by residents. Conclusion: Better trained professionals and professionals working in stable work arrangements are associated with comprehensive actions to control CC. Such strategies indicate that investments in work management result in a more organized PHC and more solution-centered work processes. Therefore, working in the PHC for a longer time and nurses performing more clinical actions (collection and treatment) are favored by such organizational actions. Investments in diagnostic support contribute to perceptions of more comprehensive actions to control CC.
\end{abstract}

Keywords: Primary health care- cervical cancer- papanicolaou test- screening- women's health- quality of health care

Asian Pac J Cancer Prev, 22 (8), 2343-2349

\section{Introduction}

Cervical cancer $(\mathrm{CC})$ is a global public health problem (GLOBOCAN, 2019), being the fourth with the highest incidence in the world. Low- and middle-income countries are the most affected, while in high-income countries, with early detection and treatment of high-grade intraepithelial lesions (HSIL), the incidence of CC is controlled (WHO, 2014; Arrossi et al., 2017).

The World Health Organization (WHO) has established a goal to eliminate the disease (Canfell et al., 2020), through the expansion of vaccinations against human papilloma virus (HPV), cervical screening, and treatment of cases of HSIL and CC (Arrossi et al., 2017), associated with programs to ensure the quality of these actions. For this, the existence of a multidisciplinary team (WHO, 2014) with stable working ties (Muramoto and Matumoto, 2019), attentive work of community health agents- CHA (Taylor et al., 2010; Fernandes et al., 2019), care coordination (Vázquez et al., 2017), integration between teaching and service (Baldoino and Veras, 2016), as well as adaptation of the structure (Bottari et al., 2008) and of the work process (Barcelos et al., 2017) are associated with quality in health actions, thus becoming central to the control of long-term illnesses such as CC.

Within the scope of programs for the control of $\mathrm{CC}$, for complex scenarios such as the Brazilian one, healthcare networks are essential to offer care in a timely and comprehensive manner, as they allow longitudinal care, which is appropriate for Brazil and has greater resolution (Brito-Silva et al., 2014). Thus, the line of care of CC makes it possible for the user to walk through the services that must be provided at the different levels of the network, by means of continuous streams that provide full care (Galvão et al., 2019).

Thus, this article assesses the quality of actions to control cervical cancer and its correlates, in the interior of Bahia, Brazil. 


\section{Materials and Methods}

\section{Methods}

Cross-sectional research conducted in 19 municipalities (641,560 inhabitants) in the interior of Bahia, Brazil, from January to March 2019. CC was used as a tracer condition to assess actions necessary for the quality of care (Bottari et al., 2008) provided by PHC professionals. These municipalities cover a large part of the population living in rural areas and, therefore, many professionals working in large rural areas with great social inequality.

\section{Population studied}

The sample consisted of 354 doctors and nurses. A prevalence of $50 \%$ for unknown events and a confidence level of $95 \%$ were used, obtaining a minimum sample of 240 professionals, considering $30 \%$ for losses. A random draw was performed considering the number of professionals registered in the PHC teams in each municipality. Professionals who were not working (vacation, leave, etc.) during the study period were excluded.

Individual interviews were conducted using questionnaires. The questionnaire was adapted from an instrument used to assess care coordination in health regions (Souza et al., 2015), to which information from national protocols were included (Brazil, 2013; Brazil, 2016).

\section{The quality of actions}

Three dependent variables were chosen to evaluate the actions developed to control CC in the day-to-day of professionals: "Performance of educational, promotion, prevention, and monitoring actions" (D1); "Access to diagnostic tests" (D2); "Non-occurrence of HSIL" (D3). These variables represent some of the criteria for the actions required by the health service system to ensure a quality program for CC control.

D1- obtained from the combination of educational and monitoring actions: "Conducting home visits to mobilize women to carry out preventive measures"; "Carrying out health education actions"; "Conducting joint efforts to expand access to cytopathological examination"; "Recording women who underwent examination at the PHC"; "monitoring the record to identify women with delayed or altered exams" and "Active search of women with delayed collection or altered results."

The following promotion and prevention actions were also considered: "Cytopathological examination collection" and "Women's access to colposcopy." The response options for the actions were "yes/no." Positive responses were used for the event, and all actions were classified as being of adequate quality, since they are constituent elements of a comprehensive CC prevention and control program (Brazil, 2013; WHO, 2014; Brazil, 2016).

D2- "Access to diagnostic tests"- obtained from the combination of responses to actions perceived by professionals regarding "Access to women with lesions prior to biopsy" and/or "Access of women with lesions prior to histopathology." The responses were dichotomized into "always/sometimes or never." The answer "always" was used in all questions, as access to diagnostic tests are fundamental to stop the development of CC and, therefore, to achieve the desired quality (Brazil, 2013; Brito-Silva et al., 2014; WHO, 2014; Brazil, 2016).

D3- "Non-occurrence of HSIL"- It was considered that a quality program can prevent the occurrence of high-grade lesions (Brazil, 2013; Goss et al., 2013; WHO, 2014; Brazil, 2016). This dependent variable was obtained by questioning about the "Presence of women diagnosed with HSIL in the PHC," whose response options were "yes/no," using negative answers.

\section{Independent variables}

The selected independent variables are shown in Figure 1, according to the blocks "Characterization and professional training," "Organization of the unit and access to cytopathological examination," and "Care coordination and integrated care."

\section{Statistical analysis}

Descriptive analyses were obtained using absolute and relative frequency measurements. For bivariate analysis, the differences between the proportions were assessed by the $\chi^{2}$ Pearson test. The analysis of factors correlated to the dependent variables (D1, D2 and D3) was performed using Poisson regression with robust variance, estimating the prevalence ratio (PR), p-value, and the $95 \%$ confidence interval $(95 \% \mathrm{CI})$. Variables with a significance level $\leq 0.20$ were included in the multivariate model.

Possible correlations between independent variables and D1, D2 and D3 were measured using different models adjusted through the hierarchical entry of the variables (Figure 1). Initially, the association between each dependent variable and the dimension I variables were evaluated, the dimension II variables were included in the second model, and the dimension III variables were included in the third model. The models were compared by the Akaike's Information Criterion (AIC) test.

The variables of the most distal blocks remained as adjustment factors for the hierarchically lower blocks. For the interpretation of the results, the identification of a statistically significant association $(\mathrm{p} \leq 0.05)$ between each factor studied and the D1, D2 and D3, after adjusting for the potential factors of the same block and the upper hierarchical blocks, indicate the existence of an independent effect, specific to that factor. The Stata statistical package version 15.0 was used for data analysis.

The research was approved by the Research Ethics Committee of the Federal University of Bahia (opinion No. 624,168).

\section{Results}

The prevalence of D1 was 39.8\% (95\% CI 33.8-46.2), whereas for D2 and D3, it was 73.9\% (95\% CI 67.9-79.1) and $46.4 \%$ (95\% CI 39.9-53.0), respectively.

About 109 doctors and 132 nurses were interviewed. Table 1 describes the PHC teams. Regarding the length of experience, $56.4 \%$ of professionals were in $\mathrm{PHC}$ for $\geq 2$ years and $43.6 \%$ reported having a inadequate 
employment model, through political indication or other precarious methods of entry. Regarding training, 59.6\% reported having participated in professional courses addressing the topic (Table 1).

With regard to the way the $\mathrm{PHC}$ is organized to provide access to users, almost all of them had doctors and nurses $(94.6 \%)$, the highest frequency in which cytopathological examination was offered was at least weekly (67.7\%) and the main method of recording was the simultaneous use of physical and electronic medical records (40.7\%). Most CHA scheduled cytopathological examinations (90.4\%), students/residents did not perform the collection even when accompanied by their preceptors $(83.1 \%)$, and nurses did not treat low-grade lesions (62.1\%). The evaluation of examination collection was positive $(77.7 \%)$ and medical transportation was accessible to women $(65.5 \%)$ (Table 1).

The professionals monitored the service trajectory of women, verifying adherence to treatment at the specialized service $(76.4 \%)$, the cytopathological and histopathological reports issued by the reference laboratory were reliable (59.4\%), and women had access to high-frequency surgery (HFS) $(71.0 \%)$ in cases of lesions being confirmed after colposcopy (Table 1).

In the bivariate analysis, in the dimension of "Characterization and professional training," there was a positive association between: time working in PHC $\geq 2$ years (D1 and D3); having entered through public tender (D1 and D2), and having professional training on the topic (D1) (Table 1).

In the dimension "PHC organization and access to cytopathology," the correlations were: form of registration (D3), collection by students (D1, D2 and D3), and treatment of low grade squamous intraepithelial lesion (LSIL) by a nurse (D1 and D2). The professional evaluation of the collection as adequate (D1 and D2) and the woman having access to medical transportation (D1) (Table 1).

In the dimension "Care coordination and integrated services," the associations were: professionals who followed the service trajectory of the women verifying adherence to treatment in the specialized service (D1 and D2), evaluation of the reports issued by the reference laboratory as reliable (D1) and women having access to HFS (D1) (Table 1).

In the multivariate analysis (Table 2), the following remained correlated: working in PHCs in the municipality ( $\geq 2$ years) (D1 and D3), having joined the service through public tender (D1 and D2), having professional training on the topic (D1), the recording of cytopathological examinations using a physical medical record (D2 and D3) or an electronic medical record (D3), collection of the cytopathological examination by students (D2 and D3), nurses performing LSIL treatment (D2), evaluation of the cytopathological collection as adequate (D1), and women having access to medical transportation (D1).

\section{Discussion}

Our findings suggest a moderate quality in actions necessary for comprehensiveness for CC control, since the diagnostic access, although surprisingly

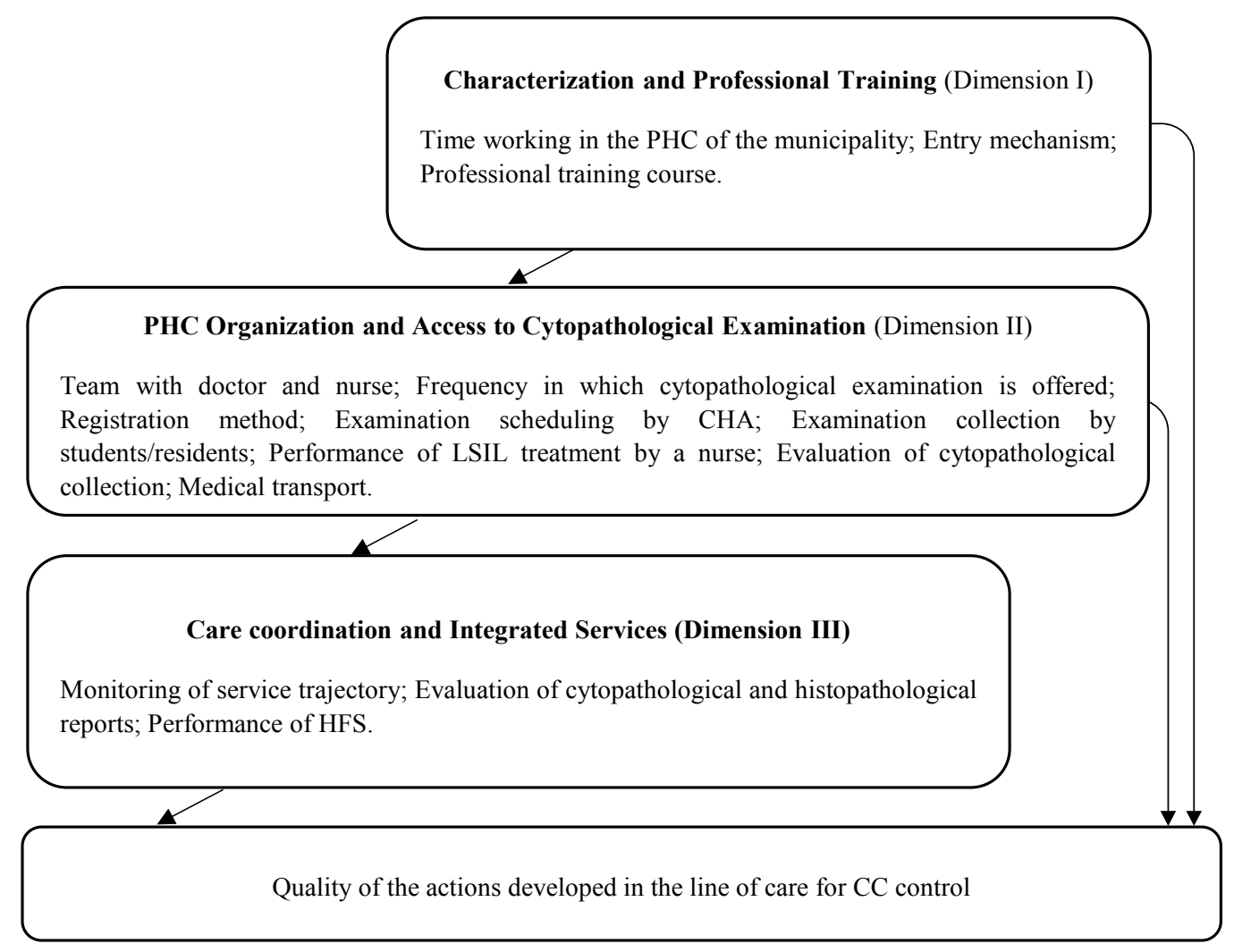

Figure 1. Hierarchical Conceptual Model of Quality Analysis of the Actions Developed in the Line of Care for Cervical Cancer Control. Abbreviations: PHC, Primary Health Care; CHA, Community Health Agents; LSIL, Low Grade Squamous Intraepithelial Lesion; HFS, High Frequency Surgery; CC, Cervical Cancer. 
Table 1. Sample Description and Bivariate Analyzes between D1, D2, D3 and Dimension I, II, and III Variables, Bahia, Northeast, Brazil, 2019.

\begin{tabular}{|c|c|c|c|c|c|c|c|}
\hline \multirow[t]{2}{*}{ Variable } & \multirow{2}{*}{$\begin{array}{c}\text { Sample } \\
\text { distribution } \\
\text { N (\%) }\end{array}$} & \multicolumn{2}{|c|}{$\begin{array}{l}\mathrm{CC} \text { educational, promotion, prevention, } \\
\text { and monitoring actions }\end{array}$} & \multicolumn{2}{|c|}{$\begin{array}{c}\text { Access } \\
\text { to diagnostic tests }\end{array}$} & \multicolumn{2}{|c|}{$\begin{array}{c}\text { Non-occurrence of } \\
\text { HSIL }\end{array}$} \\
\hline & & $\mathrm{P}(\%)$ & $\mathrm{p}$-value & $\mathrm{P}(\%)$ & p-value & $\mathrm{P}(\%)$ & $\mathrm{p}$-value \\
\hline \multicolumn{8}{|c|}{ Characterization and professional training (dimension I) } \\
\hline Occupation & & & $<0.001$ & & 0.303 & & 0.146 \\
\hline Physician & $109(45.2)$ & 23.9 & & 77.1 & & 52.2 & \\
\hline Nurse & $132(54.8)$ & 53.0 & & 71.2 & & 42.3 & \\
\hline Time working in the PHC of the city & & & $<0.001$ & & 0.053 & & 0.001 \\
\hline$<2$ years & $105(43.6)$ & 22.9 & & 67.6 & & 59.3 & \\
\hline$\geq 2$ years & $136(56.4)$ & 52.9 & & 78.7 & & 37.4 & \\
\hline Entry mechanism & & & $<0.001$ & & 0.051 & & 0.048 \\
\hline Indication or other & $105(43.6)$ & 32.4 & & 69.5 & & 50.0 & \\
\hline Public selection & $83(34.4)$ & 31.3 & & 71.1 & & 52.1 & \\
\hline Public tender & $53(22)$ & 67.9 & & 86.8 & & 31.4 & \\
\hline Professional training course & & & $<0.001$ & & 0.074 & & 0.059 \\
\hline No & $97(40.4)$ & 25.8 & & 68.0 & & 54.0 & \\
\hline Yes & $143(59.6)$ & 49.7 & & 78.3 & & 41.0 & \\
\hline \multicolumn{8}{|c|}{ PHC organization and access to cytopathological examination (dimension II) } \\
\hline Team with doctor and nurse & & & 0.144 & & 0.696 & & 0.269 \\
\hline No & $13(5.4)$ & 61.5 & & 69.2 & & 30.8 & \\
\hline Yes & $228(94.6)$ & 38.6 & & 74.1 & & 47.4 & \\
\hline \multicolumn{2}{|c|}{ Frequency in which cytopathological examination is offered } & & 0.316 & & 0.637 & & 0.991 \\
\hline Monthly & $22(9.9)$ & 27.3 & & 72.7 & & 44.4 & \\
\hline Fortnightly & $50(22.4)$ & 42.0 & & 80.0 & & 44.9 & \\
\hline Weekly or more frequently & $151(67.7)$ & 44.4 & & 73.5 & & 45.7 & \\
\hline Registration method & & & 0.367 & & 0.088 & & 0.024 \\
\hline Both & $98(40.7)$ & 34.7 & & 66.3 & & 57.1 & \\
\hline Physical medical record (on paper) & $48(19.9)$ & 42.1 & & 79.2 & & 35.6 & \\
\hline Electronic medical record & $95(39.4)$ & 45.8 & & 79.0 & & 40.7 & \\
\hline Examination scheduling by CHA & & & 0.162 & & 0.493 & & 0.686 \\
\hline No & $22(9.6)$ & 27.3 & & 81.8 & & 50.0 & \\
\hline Yes & $206(90.4)$ & 42.7 & & 75.2 & & 45.5 & \\
\hline Examination collection by students/res & & & $<0.001$ & & 0.004 & & 0.005 \\
\hline No & $197(83.1)$ & 35.0 & & 71.1 & & 50.6 & \\
\hline Yes & $40(16.9)$ & 65.0 & & 92.5 & & 25.6 & \\
\hline LSIL treatment performed by a nurse & & & 0.001 & & 0.003 & & 0.058 \\
\hline No & $146(62.1)$ & 32.2 & & 67.8 & & 50.8 & \\
\hline Yes & $89(37.9)$ & 53.9 & & 85.4 & & 37.7 & \\
\hline Assessment of cytopathological examir & & & 0.001 & & 0.053 & & 0.973 \\
\hline Inadequate or partially adequate & $52(22.3)$ & 21.2 & & 65.4 & & 45.8 & \\
\hline Totally adequate & $181(77.7)$ & 46.4 & & 78.5 & & 45.6 & \\
\hline Medical transport & & & 0.001 & & 0.143 & & 0.682 \\
\hline Never or sometimes & $699(34.5)$ & 26.1 & & 66.7 & & 47.5 & \\
\hline Always & $131(65.5)$ & 50.4 & & 76.3 & & 44.4 & \\
\hline \multicolumn{8}{|c|}{ Coordination of care and integrated services (dimension III) } \\
\hline monitoring of service trajectory & & & 0.016 & & 0.047 & & 0.058 \\
\hline Never or sometimes & $55(23.6)$ & 27.3 & & 65.5 & & 57.1 & \\
\hline Always & $178(76.4)$ & 45.5 & & 78.7 & & 41.8 & \\
\hline \multicolumn{2}{|c|}{ Evaluation of cytopathological and histopathological reports } & & 0.013 & & 0.215 & & 0.765 \\
\hline Partially reliable or I do not trust & $95(40.6)$ & 30.5 & & 70.5 & & 46.6 & \\
\hline Totally reliable & $139(59.4)$ & 46.8 & & 77.7 & & 44.5 & \\
\hline Performance of HFS & & & $<0.001$ & & 0.140 & & 0.313 \\
\hline Never or sometimes & $45(29.0)$ & 20.0 & & 75.6 & & 47.5 & \\
\hline Always & $110(71.0)$ & 56.4 & & 85.5 & & 38.3 & \\
\hline
\end{tabular}


Table 2. Multivariate Analysis of Factors Correlated with "CC Educational, Promotion, Prevention, and Monitoring Actions," "Access to Diagnostic Tests," and "Non-Occurrence of HSIL," Bahia, Northeast, Brazil, 2019.

\begin{tabular}{|c|c|c|c|c|c|c|}
\hline \multirow[t]{2}{*}{ Variable } & \multicolumn{2}{|c|}{$\begin{array}{l}\text { CC educational, promotion, prevention, } \\
\text { and monitoring actions }\end{array}$} & \multicolumn{2}{|c|}{ Access to diagnostic tests } & \multicolumn{2}{|c|}{ Non-occurrence of HSIL } \\
\hline & PR & $95 \% \mathrm{CI}$ & PR & $95 \% \mathrm{CI}$ & PR & $95 \% \mathrm{CI}$ \\
\hline \multicolumn{7}{|c|}{ Characterization and professional training (dimension I) * } \\
\hline \multicolumn{7}{|l|}{ Time working in the $\mathrm{PHC}$ of the city } \\
\hline$<2$ years & 1.00 & & & & 1.00 & \\
\hline$\geq 2$ years & 1.75 & $1.15-2.66$ & & & 1.54 & $1.16-2.04$ \\
\hline \multicolumn{7}{|l|}{ Entry mechanism } \\
\hline Indication or Other & 1.00 & & 1.00 & & & \\
\hline Public selection & 0.93 & $0.62-1.40$ & 1.02 & $0.85-1.23$ & & \\
\hline Public tender & 1.52 & $1.07-2.15$ & 1.25 & $1.06-1.47$ & & \\
\hline \multicolumn{7}{|l|}{ Professional training course } \\
\hline No & 1.00 & & & & & \\
\hline Yes & 1.49 & $1.02-2.18$ & & & & \\
\hline \multicolumn{7}{|c|}{ PHC organization and access to cytopathological examination (dimension II) $\dagger$} \\
\hline \multicolumn{7}{|l|}{ Registration method } \\
\hline Both & & & 1.00 & & 1.00 & \\
\hline Electronic medical record & & & 0.91 & $0.74-1.11$ & 1.43 & $1.05-1.95$ \\
\hline Physical medical record (on paper) & & & 0.77 & $0.63-0.94$ & 1.60 & $1.15-2.22$ \\
\hline \multicolumn{7}{|c|}{ Examination collection by students/residents } \\
\hline No & & & 1.00 & & 1.00 & \\
\hline Yes & & & 1.32 & $1.11-1.56$ & 1.65 & $1.21-2.25$ \\
\hline \multicolumn{7}{|l|}{ LSIL treatment performed by a nurse } \\
\hline No & & & 1.00 & & & \\
\hline Yes & & & 1.18 & $1.02-1.37$ & & \\
\hline \multicolumn{7}{|c|}{ Assessment of cytopathological examination collection } \\
\hline Inadequate or partially adequate & 1.00 & & & & & \\
\hline Totally adequate & 2.00 & $1.06-3.75$ & & & & \\
\hline \multicolumn{7}{|l|}{ Medical transport } \\
\hline Never or sometimes & 1.00 & & & & & \\
\hline Always & 1.61 & $1.04-2.48$ & & & & \\
\hline \multicolumn{7}{|c|}{ Care coordination and integrated services (dimension III) $\ddagger$} \\
\hline \multirow[t]{3}{*}{ Akaike criteria } & 3.558 .913 & & 4.683 .768 & & 3.854 .261 & \\
\hline & 2.964 .822 & & $4,578,194$ & & 3.803 .587 & \\
\hline & 2.964 .822 & & $4,578,194$ & & 3.803 .587 & \\
\hline
\end{tabular}

CC, Cervical Cancer; HSIL, High-Grade Intraepithelial Lesion; PHC, Primary Health Care; LSIL, Low Grade Squamous Intraepithelial Lesion. * Adjusted between the dimension I variables; $\uparrow$ Adjusted between the dimensions I and II variables; $\ddagger$ Adjusted between the dimensions I, II, and III variables.

high, coexisted with the frequent occurrence of LSIL. Contradictorily, prevention and monitoring actions had a low prevalence. Therefore, there are indications that it is necessary to improve the educational and monitoring actions of $\mathrm{CC}$, which, in turn, could led to a decrease in cases of HSIL and, to a large extent, of CC (Romli et al, 2020). Furthermore, the screening program and the early detection of lesions (diagnosis) may have no impact on the incidence of $\mathrm{CC}$ if they are not associated with treatment (WHO, 2014; Sarfati et al., 2019).

The high turnover of doctors is a major problem in Northeast Brazil (Gonçalves et al., 2019) resulting from the greater concentration of resources and services in capitals and regional hubs (Albuquerque et al., 2017), which compromises timely access and continuity of care.
Working for a longer time in PHCs in the same municipality and having joined the service through public tender represent a lower professional turnover and better labor links, allowing the formation of a community link (Muramoto and Matumoto, 2019). Furthermore, the establishment of trust with professionals increases the adherence of women and the resolution of cases, especially for care associated with sexuality, which, due to moral values, can interfere with the perception of risk and become a symbolic barrier to access (Rico and Iriart, 2013). Furthermore, satisfaction with work and wages favor care coordination (Vázquez et al., 2017).

The training of professionals through the provision of in-service education is a recommendation of global and national guidelines for better quality and resoluteness in 
services provided to the community (WHO, 2014; Brazil, 2016). Well-trained professionals guide their actions by safe evidence and gain confidence in clinical practices, mitigating unnecessary referrals and improving PHC attributes (Leão and Caldeira, 2011).

Regarding PHC organization and access to cytopathological examination, the registration method is an aspect of the work dynamics that allows for more adequate tracking, in addition to better management and informational coordination of care. The use of electronic medical records represents an advance in the communication mechanisms resulting in greater satisfaction and trust of users (Wali et al., 2020). Better communication between care levels is crucial for chronic conditions in systems with limited resources (Sarfati et al., 2019), as they facilitate care (Rahal et al., 2019), allowing longitudinal and articulated monitoring.

The performance of the examination collection by students/residents is a strong indicator of the integration between teaching and service, which promotes a better quality of service, because, in addition to providing greater access to screening exams, it also allows the service professionals to be up to date. Furthermore, it encourages the early development of professional skills and proactive attitudes of students, enables the training of professionals committed to innovation and adequate performance in complex contexts, combining theory and practice, which are essential for critical thinking and a broader view of care in health (Botti and Rego, 2011; Baldoino and Veras, 2016).

The performance of LSIL treatment by a nurse shows the relevance of this professional for the operationalization of cases in PHC (Fernandes et al., 2019). This is encouraged in different countries to expand the scope of actions in PHC and the ability to meet users' needs (Toso et al., 2016). The involvement of nurses in screening increases the confidence and adherence of vulnerable women (Perks et al., 2018).

The professional assessment of the collection of the cytopathological examination is an indicator that can provide data on the quality of teamwork and the confidence of professionals in their co-workers. Services where there is greater connection and a better working environment among the team tend to be more innovative, resolute, and better evaluated by users, especially with chronic conditions (Proudfoot et al., 2007). A better work environment results in integration and motivation for work, as well as reciprocity between team members and forging a collaborative network (Peruzzo et al., 2019).

The access of women to medical transport is fundamental for the quality of services in a network with a strong governance and logistical system, since the treatment of CC, and in some cases of HSIL, is carried out outside the municipality of residence. CC mainly affects women with lower incomes and from rural areas (Goss et al., 2013), thus, medical transport is an organizational component for reducing access inequities, decreasing user absenteeism.

For this article, analyzes were performed with hierarchical entry of the variables, which is a strategy to deal with a greater number of explanatory variables.
The inclusion of the variables and the conceptual model constructed considered the data available in the national (Brazil, 2016) and international literature (WHO, 2014). It is highly likely that these data can be generalized, considering most small municipalities in Brazil, even to networks with similar contexts, especially in Northern and Northeastern Brazil. Studies in small municipalities in Northeastern Brazil are crucial for increasing the understanding and promoting interventions in the public health system, which will make it more comprehensive and make $\mathrm{CC}$ control feasible.

\section{Author Contribution Statement}

Study design: Anjos EF, Santos AM. Data collection: Anjos EF. Data analysis and interpretation: Anjos EF, Martins PC, Bezerra VM, Almeida PF, Santos AM. Discussion of the results: Anjos EF, Martins PC, Almeida PF, Santos AM. Writing and/or critical review of the content: Anjos EF, Martins PC, Prado NMBL, Bezerra VM, Almeida PF, Santos AM. All authors approved the final version.

\section{Acknowledgments}

We thank the Coordination for the Improvement of Higher Education Personnel (CAPES) and the Research Support Foundation of the State of Bahia (FAPESB) for funding this research. We thank the Primary Health Care managers who made it possible to carry out the interviews with doctors and nurses from PHC. We thank the Bahia State Observatory of Healthcare Networks for support in the study design and data collection. Finnaly, we thank the National Council for Scientific and Technological Development - CNPq for its support to Almeida PF through the Productivity in Research Scholarship (PQ).

\section{Funding statement}

Anjos EF received financial support from the Coordination for the Improvement of Higher Education Personnel - Brazil (CAPES) - funding code 001. This study was funded by the Research Support Foundation of the State of Bahia (FAPESB) through Public Notice No. 08/2015 - Support for Research Projects for Young Scientists in the State of Bahia (Grant Term JCB0003/2016).

\section{Origin of the article}

This article was extracted from the thesis entitled "Evaluation of the Quality of the Cervical Cancer Control Actions in a Health Region of Northeastern Brazil".

\section{Ethical approval}

Ethical approval for the study was obtained from the Research Ethics Committee of the Federal University of Bahia, Brazil.

\section{Data availability statement}

All data generated or analysed during this study are in the custody of the researchers and will be made available upon request. 
Statement on conflict of interest

There is no conflict of interests.

\section{References}

Albuquerque MV, Viana ALD, Lima LD, et al (2017). Regional health inequalities: changes observed in Brazil from 2000-2016. Regional health inequalities: changes observed in Brazil from 2000-2016. Cien Saude Colet, 22, 1055-64.

Arrossi S, Temin S, Garland S, et al (2017). Primary prevention of cervical cancer: American Society of Clinical Oncology Resource-Stratified Guideline. J Glob Oncol, 5, 611-34.

Baldoino AS, Veras RM (2016). Analysis of Service-learning activities adopted in health courses of Federal University of Bahia. Rev Esc Enferm USP, 50, 17-24.

Barcelos MRB, Lima RCD, Tomasi E, et al (2017). Quality of cervical cancer screening in Brazil: external assessment of the PMAQ. Rev Saude Publica, 51, 67.

Botti SHO, Rego STA (2011). Lecturer-clinician: the complex role of the preceptor in medical residency. Physis, 21, 65-85.

Bottari CMS, Vasconcellos MM, Mendonça MHM (2008). Cervical cancer as a tracer condition: a proposal for evaluation of primary health care. Cad Saude Publica, 24, 111-22.

Brito-Silva K, Bezerra AF, Chaves LD, Tanaka OU (2014). Integrality in cervical cancer care: evaluation of access. Rev Saude Publica, 48, 240-8.

Canfell K, Kim JJ, Brisson M, et al (2020). Mortality impact of achieving WHO cervical cancer elimination targets: a comparative modelling analysis in 78 low-income and lowermiddle-income countries. Lancet, 395, 591-603.

Fernandes NFS, Galvão JR, Assis MMA, Almeida PF, Santos AM (2019). Access to uterine cervical cytology in a health region: invisible women and vulnerable bodies. Cad Saude Publica, 35, e00234618.

Galvão JR, Almeida PF, Santos AM, Bousquat A (2019). Healthcare trajectories and obstacles faced by women in a health region in Northeast Brazil. Cad Saude Publica, 35, e00004119.

Global Burden of Disease Cancer Collaboration. Fitzmaurice C, Abate D, Abbasi N, et al (2019). Global, Regional, and National Cancer Incidence, Mortality, Years of Life Lost, Years Lived With Disability, and DisabilityAdjusted Life-Years for 29 Cancer Groups, 1990 to 2017: A Systematic Analysis for the Global Burden of Disease Study. JAMA Oncol, 5, 1749-68.

Gonçalves RF, Bezerra AFB, Tanaka OY, et al (2019). Influence of the Mais Médicos (More Doctors) program on health services access and use in Northeast Brazil. Rev Saude Publica, 53, 110.

Goss PE, Lee BL, Badovinac-Crnjevic T, et al (2013). Planning cancer control in Latin America and the Caribbean. Lancet Oncol, 14, 391-436.

Leão CD, Caldeira AP (2011). Assessment of the association between the qualification of physicians and nurses in primary healthcare and the quality of care. Cien Saude Colet, 16, 4415-23.

Ministry of Health. Brazil (2013). Control of cervical and breast cancers. Brasília, Ministry of Health. http://bvsms.saude.gov. br/bvs/publicacoes/controle_canceres_colo_utero_2013.pdf, accessed November 2019.

Muramoto FT, Matumoto S (2019). Repercussions of the Brazilian program for the assessment of quality of primary care. Rev Cuba Enf, 35, 1-17.

National Cancer Institute José Alencar Gomes da Silva. Brazilian guidelines for cervical cancer screening. INCA, 2016. https://www.inca.gov. $\mathrm{br} /$ sites/ufu.sti.inca.local/files//media/document// diretrizesparaorastreamentodocancerdocolodoutero_2016 corrigido.pdf, accessed November 2019.

Perks J, Algoso M, Peters K (2018). Nurse practitioner (NP) led care: cervical screening practices and experiences of women attending a women's health centre. Collegian, 25, 493-9.

Peruzzo HE, Silva ES, Batista VC, et al (2019). Organizational climate and teamwork at the Family Health Strategy. Rev Bras Enferm, 72, 721-7.

Proudfoot J, Jayasinghe UW, Holton C, et al (2007). Team climate for innovation: what difference does it make in general practice?. Int J Qual Health Care, 19, 164-9.

Rahal RM, Mercer J, Kuziemsky C, Yaya S (2019). Primary care physicians' experience using advanced electronic medical record features to support chronic disease prevention and management: Qualitative Study. JMIR Med Inform, 7, e13318.

Rico AM, Iriart JÁ (2013).”Where there's a woman, there's a Pap smear": the meanings assigned to cervical cancer prevention among women in Salvador, Bahia State, Brazil. Cad Saude Publica, 29, 1763-73.

Romli R, Shahabudin S, Saddki N, Mokhtar N (2020). Effectiveness of a health education program to improve knowledge and attitude towards cervical cancer and pap smear: A Controlled Community Trial in Malaysia. Asian Pac J Cancer Prev, 21, 853-9.

Sarfati D, Dyer R, Sam FA, et al (2019). Cancer control in the Pacific: big challenges facing small island states. Lancet Oncol, 20, 475-92.

Souza MKB, Almeida PF, Santos AM,et al (2015). Research strategies and methods on Primary Health Care in the coordination of care in regionalized networks. In 'Primary health care in the coordination of care in health regions'. Almeida PF, Santos AM, Souza MKB. Salvador, Edufba pp. 117-45.

Taylor VM, Jackson JC, Yasui Y, et al (2010). Evaluation of a cervical cancer control intervention using lay health workers for Vietnamese American women. Am J Public Health, 100, 1924-9.

Toso BRGO, Filippon J, Giovanella L (2016). Nurses' performance on primary care in the National Health Service in England. Rev Bras Enferm, 69, 169-77.

Vázquez ML, Vargas I, Garcia-Subirats I, et al (2017). Doctors' experience of coordination across care levels and associated factors. A cross-sectional study in public healthcare networks of six Latin American countries. Soc Sci Med, 182, 10-9.

Wali RM, Alqahtani RM, Alharazi SK, Bukhari SA, Quqandi SM (2020). Patient satisfaction with the implementation of electronic medical Records in the Western Region, Saudi Arabia, 2018. BMC Fam Pract, 21, 37.

World Health Organization (2014). Comprehensive cervical cancer control. A guide to essential practice, Geneva, World Health Organization.

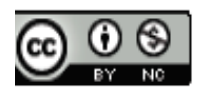

This work is licensed under a Creative Commons AttributionNon Commercial 4.0 International License. 